\title{
Humanities \& Social Sciences

ARTICLE

\section{Effect of agency costs on the optimal matching grant rate in a model of tax competition with benefit spillovers}

Tong Yang (1D ${ }^{1 \times}$

Agency problems arise in any environment involving a principal-agent relationship. This study examines the effect of horizontal fiscal externalities on the optimal matching grant rate in a model where agency costs are inevitable. Because this study takes agency costs into account, the main results should differ from the standard conclusions of the tax competition literature. This study finds that the degree of agency costs and benefit spillovers determine the relationship between tax competition and the optimal matching grant rate. If agency costs are relatively small, and benefit spillover is zero, the optimal matching grant rate should increase with the factors of production demand elasticities with respect to the factor tax rate and vice versa. Tax competition thus may ease the inefficiency arising from agency costs only if the disutility of effort is so large that the benefits from tax competition exceed the costs when benefit spillover is zero. 


\section{Introduction}

gency problems arise in any environment involving principal-agent relationships. Following the theory of agency, if the principal hopes to ensure that the agent will make decisions that are optimal for the principal rather than the agent themselves, the differing objectives of the pair make agency costs inevitable. This issue not only applies to firm ownership structure, but also to the political agency process. Numerous recent studies have analysed agency problems. Jensen and Meckling (1976) explain that agency costs arise in any environment without cooperation between agent and principal. Besley and Case (1995) demonstrate that the incumbent will improve his welfare by investing less effort, contradicting the objectives of voters. The marginal disutility of effort incurring agency costs can be resolved by the threats to the government's re-election (see, e.g., Seabright, 1996). Belleflamme and Hindriks (2005) observe that yardstick competition between jurisdictions exerts both discipline and sorting effects within the political agency framework. Voters can mitigate agency costs below the Leviathan level by adopting a successful voting strategy (as noted by Wrede, 2001).

Dahlby (1996) has analysed agency problems for the case of fiscal externalities. Both direct and indirect fiscal externalities can be corrected by matching revenue, matching expenditure or equalisation grants devised by the state and federal governments. Within the vertical fiscal externalities framework, Dahlby and Wilson (2003) show that the jurisdictional government will underprovide or overprovide local public goods depending on the assumptions made. Furthermore, when one considers a model of fiscal federalism featuring both vertical and horizontal fiscal externalities, as Brülhart and Jametti (2019) have observed, tax competition can represent second-best efficient Leviathan taming by constraining the scope for public-sector revenue maximisation. Following Zodrow and Mieszkowski (1986), local public goods provided by local governments are underprovided through interregional property tax competition. Therefore, if lump-sum tax cannot be operated by the local government, the underprovision of local public goods financed by the distortionary tax is inevitable in a standard model of tax competition. To solve this issue, it is often argued that an intergovernmental matching grant devised by the federal government can be introduced to ease the exorbitant marginal cost of local public funds deriving from the downward pressure on tax rates, assuming that the federal government is benevolent and omniscient (see, e.g., Dahlby, 1996).

In the discussion of the spillover effect of local public goods among jurisdictions, the prevailing view is that spillover will aggravate the under-provision of such goods (see e.g. Boadway et al., 1989). However, an alternative opinion on this problem is that the spillover effect of local public goods may alleviate the under-provision of such goods in some situations. Ogawa (2006) argues that the matching grant rate may decrease with spillover effect if the elasticity of capital with respect to the capital tax rate is significant in a tax competition model. Kawachi and Ogawa (2006) find that local governments are more inclined to provide local public goods efficiently given a sufficient spillover effect in a repeated-game model with large homogeneous jurisdictions.

The literature (see, e.g., Belleflamme and Hindriks, 2005; Besley and Case, 1995) emphasises agency problems and confirms that agency costs can raise the marginal cost of local public goods provided in jurisdictions. Consequently, jurisdictions will experience an undersupply of local public goods if the marginal benefit of local public funds is unaffected by a given issue. However, few studies deal with agency problems in situations involving horizontal tax externalities. One example of such a study is Nishigaki and Kato (2016), who show that yardstick competition in the small jurisdictions model generates additional costs of financing public goods and increases the seriousness of the under-provision of public goods caused by tax competition. In contrast to their approach, this paper finds that tax competition mitigates the under-provision of local public goods if agency costs are large enough. Accordingly, the optimal matching grant rate devised by the federal government should decrease with the intensiveness of tax competition, considering the large agency costs.

In this study, we introduce tax competition and benefit spillovers into the model to generalise the effect of horizontal fiscal externalities and benefit spillovers leading to under-provision of public goods on the agency cost problem.

This paper is organised as follows. The inefficiency of the agency cost problem in a closed economy with consumption spillover effect among jurisdictions is set out in the section "The model". We introduce tax competition into the model in the section "The introduction of tax competition" to generalise the effect of horizontal fiscal externalities leading to under-provision of public goods on the agency cost problem. Finally, the section "Conclusion" draws conclusions.

\section{The model}

In this section, we start with the case where private capital is not mobile. There are $n$ identical local jurisdictions, where each jurisdiction $i(=1,2, \ldots, n)$ has a single immobile resident, and preferences are defined by a strictly quasi-concave utility function $U_{i}\left(x_{i}, G_{i}\right)$, where $x_{i}$ is the consumption of a private numeraire good and $G_{i}$ is the local public good. The local public good consumption in jurisdiction $i$ is defined by

$$
G_{i}=g_{i}+\beta \sum_{j \neq i} g_{j}
$$

where $g_{i}$ is the provision of the local public good by the jurisdictional government $i$, and $\beta(0 \leqq \beta \leqq 1)$ indicates the degree of benefit spillover. We assume that the jurisdictional governments are partly self-interested. Therefore, the welfare function of jurisdictional government $i$ is written by $W_{i}=V_{i}\left[X_{i}\left(g_{i}\right)\right]+U_{i}\left(G_{i}, x_{i}\right)$, where $V_{i}\left[X_{i}\left(g_{i}\right)\right]$ are the agency costs, with $V_{i}\left[X_{i}\left(g_{i}\right)\right]>0$, $V_{i}^{\prime}\left[X_{i}\left(g_{i}\right)\right]<0, V_{i}^{\prime \prime}\left[X_{i}\left(g_{i}\right)\right]<0$. Additionally, $X_{i}\left(g_{i}\right)$ denotes the variation in effort, which reflects differences in incumbent types, with $X_{i}\left(g_{i}\right)>0, X_{i}^{\prime}\left(g_{i}\right)>0, X_{i}^{\prime \prime}\left(g_{i}\right)>0^{1}$. Although the jurisdictional governments desire more excess rents, they must consider the utility of residents in their jurisdictions to ensure their own reelection and access to rents. However, the central government is assumed to be benevolent. For simplicity, we assume that the aggregate output is exogenous in each jurisdiction, and can be expressed by $y_{i}$. The jurisdictional governments impose lumpsum taxes on the resident to fund local public good provision, and the central government imposes lump-sum taxes on the resident to fund the matching grant. The budget constraint of the resident is given by

$$
x_{i}=y_{i}-z_{i}-h,
$$

where $z_{i}$ is the lump-sum tax imposed by jurisdiction $i$ and $h$ is the tax imposed by central government, which is assumed to be identical for all jurisdictions. The budget constraint of the government of jurisdiction $i$ can be given by

$$
z_{i}+s_{i}=g_{i}
$$

where $s_{i}$ is the matching grant the government of jurisdiction $i$ receives from the central government. Hence, the matching grant $s_{i}$ can be given by

$$
s_{i}=m g_{i}
$$

where $m$ is the rate of the uniform matching grant. We assume a uniform matching grant rate because the jurisdictions are 
homogeneous at the symmetric equilibrium ${ }^{2}$. Fiscal revenue finances the provision of local public goods. In Eq. (2) $h$ should satisfy the central government's budget constraint, which is given by

$$
\sum_{i=1}^{n} s_{i}=n h=\sum_{i=1}^{n} m g_{i}
$$

This model involves two stages:

In stage 1 , the central government chooses national tax rate $h$ and matching grant rate $m$.

In stage 2, the jurisdictional government $i$ chooses local tax rate $z_{i}$ and local public good $g_{i}$, taking $h$ and $m$ as given.

The central government cares about all individuals in the country, and wants to set $m$ and $h$ so as to realise efficient provision of local public goods by jurisdictional governments in a non-cooperative equilibrium, according to the Pareto-optimal condition derived below.

The jurisdictional government $i$ wishes to maximise the objective function $W_{i}$ subject to (1)-(4), taking the tax rates $z_{j}$ and the provision of local public goods of other jurisdictions $g_{j}$ as given. The maximisation problem is then defined as

$$
\begin{gathered}
\max _{g_{i}, z_{i}} W_{i}=V_{i}\left[X_{i}\left(g_{i}\right)\right]+U_{i}\left(G_{i}, x_{i}\right) \\
\text { s.t. } x_{i}=y_{i}-z_{i}-h \\
z_{i}+s_{i}=g_{i} \\
s_{i}=m g_{i} \\
G_{i}=g_{i}+\beta \sum_{j \neq i} g_{j} .
\end{gathered}
$$

We use the substitution method and differentiate $W_{i}$ with respect to $g_{i}$, and the first-order condition can be written as ${ }^{3}$

$$
\frac{\partial W_{i}}{\partial g_{i}}=V_{i}^{\prime} X_{i}^{\prime}+\frac{\partial U_{i}}{\partial G_{i}}-(1-m) \frac{\partial U_{i}}{\partial x_{i}}=0 .
$$

We have considered all jurisdictions to be identical. That is, $V_{i}^{\prime} X_{i}^{\prime}=V_{j}^{\prime} X_{j}^{\prime}, \frac{\partial U_{i}}{\partial G_{i}}=\frac{\partial U_{j}}{\partial G_{j}}$ and $\frac{\partial U_{i}}{\partial x_{i}}=\frac{\partial U_{j}}{\partial x_{j}}$. Therefore, Eq. (7) at the symmetric equilibrium can be rewritten as

$$
V^{\prime} X^{\prime}+\frac{\partial U}{\partial G}-(1-m) \frac{\partial U}{\partial x}=0,
$$

where the jurisdiction-specific subscripts $i$ and $j$ are omitted.

The Pareto-optimal condition, however, is derived by

$$
\begin{gathered}
\max _{x_{i}, g_{i}} \sum_{i=1}^{n} U_{i}(i=1,2, \ldots \ldots, n), \\
\text { s.t. } \sum_{i=1}^{n} x_{i}+\sum_{i=1}^{n} g_{i}=\sum_{i=1}^{n} y_{i},
\end{gathered}
$$

The Lagrange function is given by

$$
L\left(g_{i}, x_{i}\right)=\sum_{i=1}^{n} U_{i}+\lambda\left[\sum_{i=1}^{n} x_{i}+\sum_{i=1}^{n} g_{i}-\sum_{i=1}^{n} y_{i}\right] .
$$

Differentiating $L\left(g_{i}, x_{i}\right)$ with respect to $g_{i}$ and $x_{i}$ gives us

$$
\begin{gathered}
\frac{\partial L}{\partial g_{i}}=\frac{\partial U_{i}}{\partial G_{i}}+\beta \sum_{j \neq i} \frac{\partial U_{j}}{\partial G_{j}}+\lambda=0, \\
\frac{\partial L}{\partial x_{i}}=\frac{\partial U_{i}}{\partial x_{i}}+\lambda=0,
\end{gathered}
$$

which can be rewritten as

$$
\frac{\partial U_{i}}{\partial G_{i}}+\beta \sum_{j \neq i} \frac{\partial U_{j}}{\partial G_{j}}=\frac{\partial U_{i}}{\partial x_{i}} .
$$

We have considered all jurisdictions to be identical. Therefore, Eq. (9) at the symmetric equilibrium can be rewritten as

$$
[1+\beta(n-1)] \frac{\partial U}{\partial G}=\frac{\partial U}{\partial x},
$$

where the jurisdiction-specific subscripts $i$ and $j$ are omitted.

Comparison of Eqs. (8) and (10) shows the optimal matching grant rate which the central government should choose is given by $^{4}$

$$
m=\frac{\beta(n-1)}{1+\beta(n-1)}-\frac{V^{\prime} X^{\prime}}{U_{x}} .
$$

Recalling that $V^{\prime}<0, X^{\prime}>0$, we know from Eq. (11) that the optimal matching grant rate increases with agency costs $\left(\partial \mathrm{m} / \partial V^{\prime}\right.$ $X^{\prime}<0$ ). Besides benefit spillovers, note that agency costs may also aggravate the under-provision of local public goods in the absence of tax competition among local jurisdictions ${ }^{5}$. This finding corresponds with conclusions from the literature (e.g., see Belleflamme and Hindriks, 2005; Besley and Case, 1995). Notably, this result is an extension of Boadway et al. (1989) and Ogawa (2006) with reference to a particular case.

\section{The introduction of tax competition}

Thus far, we have shown the inefficiency of the agency cost problem in a closed economy with consumption spillover effect among jurisdictions. However, in practice, private capital is movable among jurisdictions and jurisdictional governments can raise revenue only or partly via distortional capital taxes within their own jurisdictions ${ }^{6}$. Therefore, in the present study, we now rebuild the model of tax competition in which private capital is put into production and is perfectly mobile among jurisdictions, and jurisdictional governments raise revenue not with a lumpsum tax but rather a distortional capital tax ${ }^{7}$.

As before, we assume $n$ identical jurisdictions, where each jurisdiction $i(=1,2, \ldots, n)$ has a single immobile resident providing the labour, $l_{i}=1$. The production functions in all jurisdictions are identical, and the labour is not shown explicitly in those functions. That is, the production function in jurisdiction $i$ is simply given by

$$
y_{i}=f_{i}\left(k_{i}^{\mathrm{p}}\right)
$$

where $k_{i}^{\mathrm{p}}$ is the private capital in jurisdiction $i$. Private capital has perfect mobility. Therefore, in equilibrium the after-tax return to capital is equalised across jurisdictions

$$
f_{k p}\left(k_{i}^{\mathrm{p}}\right)-t_{i}=f_{k p}\left(k_{j}^{\mathrm{p}}\right)-t_{j}=r(j \neq i)
$$

for all $i(=1,2, \ldots, n)$, where $f_{k p}\left(k_{i}^{\mathrm{p}}\right) \equiv \partial f_{i}\left(k_{i}^{\mathrm{p}}\right) / \partial k_{i}^{\mathrm{p}}>0, f_{k p k p}<0, t_{i}$ is the tax rate per unit of capital in jurisdiction $i$ and $r$ is the after tax return to private capital in the country.

The total supply of private capital in the country is fixed at $\bar{K}^{\mathrm{p}}$ such that

$$
\bar{K}^{\mathrm{p}}=\sum_{i=1}^{n} k_{i}^{\mathrm{p}} .
$$

The budget constraint of the resident is as follows:

$$
x_{i}=f_{i}\left(k_{i}^{\mathrm{p}}\right)-f_{k p}\left(k_{i}^{\mathrm{p}}\right) k_{i}^{\mathrm{p}}+r \bar{k}_{i}^{\mathrm{P}}-h,
$$

where $\bar{k}_{i}^{\mathrm{P}}$ is the initial endowment of private capital in jurisdiction $i$ and $h$ is the lump-sum tax imposed by the central government. Substituting Eq. (13) into Eq. (15), Eq. (15) can be rewritten as

$$
x_{i}=f_{i}\left(k_{i}^{\mathrm{p}}\right)-t_{i} k_{i}^{\mathrm{p}}+r\left(\bar{k}_{i}^{\mathrm{P}}-k_{i}^{\mathrm{p}}\right)-h .
$$


The jurisdictional government budget constraint is given by

$$
t_{i} k_{i}^{\mathrm{p}}+s_{i}=g_{i} .
$$

As before, the jurisdictional government $i$ receives a matching grant from the central government to provide the local public good. Hence, the following condition holds:

$$
s_{i}=m g_{i} \text {. }
$$

The lump-sum tax imposed by the central government $h$ will be set to satisfy the budget constraint of the central government, as follows: ${ }^{8}$

$$
\sum_{i=1}^{n} s_{i}=n h=\sum_{i=1}^{n} m g_{i}
$$

This model involves two stages:

In stage 1 , the central government chooses the national $\operatorname{tax} h$ and the matching grant rate $m$.

In stage 2 , the jurisdictional government $i$ chooses the local tax $t_{i}$ and the local public good $g_{i}$, taking $h$ and $m$ as given.

The jurisdictional government $i$ wishes to maximise the objective function $W_{i}$ subject to Eqs. (13)-(17), taking the tax rates $t_{j}$ and the provision of local public goods of other jurisdictions $g_{j}$ as given. Then, the maximisation problem is defined as

$$
\begin{gathered}
\max _{g_{i}, t_{i}} W_{i}=V_{i}\left[X_{i}\left(g_{i}\right)\right]+U_{i}\left(G_{i}, x_{i}\right), \\
\text { s.t. } f_{k p}\left(k_{i}^{\mathrm{p}}\right)-t_{i}=f_{k p}\left(k_{j}^{\mathrm{p}}\right)-t_{j}=r,(j \neq i) \\
x_{i}=f_{i}\left(k_{i}^{\mathrm{p}}\right)-f_{k p}\left(k_{i}^{\mathrm{p}}\right) k_{i}^{\mathrm{p}}+r \bar{k}_{i}^{\mathrm{p}}-h, \\
t_{i} k_{i}^{\mathrm{p}}+s_{i}=g_{i}, \\
s_{i}=\mathrm{m} g_{i}, \\
\bar{K}^{\mathrm{p}}=\sum_{i=1}^{n} k_{i}^{\mathrm{p}} .
\end{gathered}
$$

The first-order condition gives ${ }^{9}$

$\frac{\partial W_{i}}{\partial t_{i}}=\frac{1}{1-m} V_{i}^{\prime} X_{i}^{\prime}\left(k_{i}^{\mathrm{p}}+t_{i} \frac{\partial k_{i}^{\mathrm{p}}}{\partial t_{i}}\right)+\left\{\begin{array}{c}\frac{1}{1-m}\left(k_{i}^{\mathrm{p}}+t_{i} \frac{\partial k_{i}^{\mathrm{p}}}{\partial t_{i}}+\beta \sum_{i \neq j} t_{j} \frac{\partial k_{i}^{\mathrm{p}}}{\partial t_{i}}\right) \frac{\partial U_{i}}{\partial G_{i}}+ \\ {\left[-k_{i}^{\mathrm{p}}+\left(\bar{k}_{i}^{\mathrm{p}}-k_{i}^{\mathrm{p}}\right) \frac{\partial r}{\left.\partial t_{i}\right]} \frac{\partial U_{i}}{\partial x_{i}}\right.}\end{array}\right\}=0$.

We have considered all jurisdictions to be identical. Therefore, Eq. (20) at the symmetric equilibrium can be rewritten as

$$
V^{\prime} X^{\prime}(1-\varepsilon)+\frac{\partial W}{\partial U}\left\{[1-\varepsilon(1-\beta)] \frac{\partial U}{\partial G}-(1-m) \frac{\partial U}{\partial x}\right\}=0,
$$

where $\varepsilon$ is the private capital demand elasticity with respect to the tax rate in jurisdiction $i$, i.e., $\varepsilon \equiv-\left(\frac{\mathrm{d} k_{i}^{\mathrm{P}}}{\mathrm{d} t_{i}}\right)\left(\frac{t_{i}}{k_{i}^{\mathrm{p}}}\right) \forall i$.

As for comparison of Eqs. (8) and (10), comparison of Eqs. (21) and (10) shows the optimal matching grant rate that the central government should choose is given by

$$
m=\frac{\beta(n-1)+\varepsilon(1-\beta)}{1+\beta(n-1)}-\frac{V^{\prime} X^{\prime}(1-\varepsilon)}{U_{x}} .
$$

We assume that we are on the left side of the Laffer curve, that is, $1-\varepsilon>0$. Recalling once again that $V^{\prime}<0, X^{\prime}>0$, we know from Eq. (22) that the optimal matching grant rate increases with agency costs even given horizontal fiscal externalities among jurisdictions $\left(\partial m / \partial V^{\prime} X^{\prime}<0\right)$. Notably, this result is an extension of Ogawa (2006) with reference to a particular case.
Next, we derive the relationship between $m$ and $\varepsilon$. Differentiating $m$ with respect to $\varepsilon$, we obtain

$$
\frac{\partial m}{\partial \varepsilon}=\frac{1-\beta}{1+\beta(n-1)}+\frac{V^{\prime} X^{\prime}}{U_{x}} .
$$

To study the effects of tax competition and benefit spillovers on the optimal matching grant rate, we present the following basic rationale: Generally, the larger the factors of production demand elasticities with respect to the factor tax rates are, the more intense tax competition becomes. The marginal cost of public funds is widely considered to be larger for local jurisdictions facing a situation of tax competition and benefit spillovers. Therefore, jurisdictional governments are inclined to provide fewer local public goods under such a situation. Consequently, agency costs will decrease because $V_{i}^{\prime}\left[X_{i}\left(g_{i}\right)\right]<0$ and $X_{i}^{\prime}\left(g_{i}\right)>0$. However, the welfare of residents will be decreased owing to less provision of local public goods. This means that the utilitarian form of welfare considering agency costs in each jurisdiction significantly depends on the two effects working in the opposite direction ${ }^{10}$. For example, if agency costs and benefit spillovers are small $^{11}$, the decrease of agency costs is smaller than the decrease of the welfare of residents. The net effect is that the utilitarian form of welfare considering agency costs in each jurisdiction is decreased. Restated, the inefficiency of each jurisdiction is increased. For that reason, the matching grant rate from the central government should be increased to eliminate the inefficiency resulting from tax competition and benefit spillovers. Conversely, if agency costs are large enough, the decrease of those agency costs exceeds the decrease in the welfare of residents. The net effect is an increase in the utilitarian form of welfare considering agency costs in each jurisdiction. The inefficiency of each jurisdiction thus is mitigated. Accordingly, the matching grant rate from the central government should be decreased.

Assuming agency costs are inevitable ${ }^{12}$, we obtain the following proposition:

Proposition We assume that $1-\varepsilon>0$. The following results can be obtained:

(1) If agency costs are relatively small, that is, $1+\frac{V^{\prime} X^{\prime}}{U_{x}}>0$, and $\beta=0$, the optimal matching grant rate should increase with the private capital demand elasticities with respect to the capital tax.

(2) If agency costs are relatively small, that is, $1+\frac{V^{\prime} X^{\prime}}{U_{x}}>0$, and $\beta=1$, the optimal matching grant rate should decrease with the private capital demand elasticities with respect to the capital tax.

(3) If agency costs are relatively small, that is, $1+\frac{V^{\prime} X^{\prime}}{U_{x}}>0$, and $0<\beta<1$, the relationship between the optimal matching grant rate and the private capital demand elasticities with respect to the capital tax is ambiguous.

(4) If $\frac{V^{\prime} X^{\prime}}{U_{x}}=-1$ and $\beta=0$, no relation exists between the optimal matching grant rate and the private capital demand elasticities with respect to the capital tax.

(5) If $\frac{V^{\prime} X^{\prime}}{U^{\prime}}=-1$ and $\beta>0$, the optimal matching grant rate should decrease with the private capital demand elasticities with respect to the capital tax. This is especially so if $\frac{V^{\prime} X^{\prime}}{U_{x}}=$ -1 and $\beta=1, \frac{\partial m}{\partial \varepsilon}=-1$.

(6) If agency costs are sufficiently large, that is, $1+\frac{V^{\prime} X^{\prime}}{U_{x}}<0$, the optimal matching grant rate should decrease with the private capital demand elasticities with respect to the capital tax, independent of benefit spillovers.

The above proposition is shown in Table 1.

For instance, some simulated values for the parameters above can be considered as Table 2 .

Note that horizontal fiscal externalities originating from tax competition and benefit spillovers result in under-provision of 
local public goods (inefficiency). However, these externalities also can ease the under-provision of local public goods resulting from agency costs (inefficiency correction). These two effects simultaneously work in opposite directions. If agency costs are small and benefit spillover is zero, the former effect exceeds the latter one, meaning horizontal fiscal externalities aggravate the underprovision of local public goods. Conversely, when agency costs are small and benefit spillovers are perfect, or when agency costs are large enough, the latter effect exceeds the former one, which means horizontal fiscal externalities may ease the under-provision of local public goods. In particular, when agency costs are small and benefit spillovers are imperfect, the magnitude of the two effects will be ambiguous. Additionally, when $\frac{V I X \prime}{U_{x}}=-1$ and benefit spillover is zero, the two effects cancel each other out, which means horizontal fiscal externalities cannot affect the provision of local public goods.

\section{Conclusion}

This paper has focused on the effect of horizontal fiscal externalities on the optimal matching grant rate in a model where agency costs are inevitable. When benefit spillover is zero, the relationship between the optimal matching grant rate and private capital demand elasticities with respect to capital tax depends on agency costs. This means that the inefficiency arising from agency costs may be eased by tax competition only if the disutility of effort is so large that the benefits resulting from tax competition exceed its costs when benefit spillover is zero. However, if benefit spillovers occur among jurisdictions, the results will be ambiguous.

Note that the analysis abstracts from dynamic aspects. The ratchet effect is frequently introduced in a two-period setting where timing and commitment of policies (including capital taxes imposed by sub-central governments and matching grants from central government) matter and should also be addressed in future research.

Evidently agency costs (the disutility of effort) in providing local public goods should be set to equal the marginal increase in the probability of re-election multiplied by the value of being reelected $^{13}$. By ignoring the problems associated with re-election, we obtain some succinct results in our paper. Therefore, the

Table 1 The relationship between $m$ and $\varepsilon$.

\begin{tabular}{lllll} 
& $\mathbf{1}+\frac{\boldsymbol{V}^{\prime} \boldsymbol{X}^{\prime}}{\boldsymbol{U}_{\mathbf{x}}}<\mathbf{0}$ & $\mathbf{1}+\frac{\boldsymbol{V}^{\prime} \boldsymbol{X}^{\prime}}{\boldsymbol{U}_{\mathbf{x}}}=\mathbf{0}$ & $\mathbf{1}>\mathbf{1}+\frac{\boldsymbol{V}^{\prime} \boldsymbol{X}^{\prime}}{\boldsymbol{U}_{\mathbf{x}}}>\mathbf{0}$ & $\mathbf{1}+\frac{\boldsymbol{V}^{\prime} \boldsymbol{X}^{\prime}}{\mathbf{U}_{\mathbf{x}}}=\mathbf{1}$ \\
\hline$\beta=0$ & $\frac{\partial m}{\partial \varepsilon}<0$ & $\frac{\partial m}{\partial \varepsilon}=0$ & $\frac{\partial m}{\partial \varepsilon}>0$ & $\frac{\partial m}{\partial \varepsilon}=1$ \\
$0<\beta<1$ & $\frac{\partial m}{\partial \varepsilon}<0$ & $\frac{\partial m}{\partial \varepsilon}<0$ & $\frac{\partial m}{\partial \varepsilon}<0$ & $\frac{\partial m}{\partial \varepsilon}>0$ \\
$\beta=1$ & $\frac{\partial m}{\partial \varepsilon}<0$ & $\frac{\partial m}{\partial \varepsilon}=-1$ & $\frac{\partial m}{\partial \varepsilon}<0$ & $\frac{\partial m}{\partial \varepsilon}=0$ \\
\hline
\end{tabular}

robustness of the results should be further tested by introducing incumbent politicians into the model. In particular, we choose a simple form of social welfare function to formulate the maximisation problem. Therefore, employing a more general form of objective function and considering re-election may provide intriguing insights, an avenue that is left to future research. In addition, our model also needs the verification of empirical analysis in the future research.

Finally, we should more concretely present the policy implications of the above results. Agency costs may aggravate the under-provision of local public goods when no tax competition exists among local jurisdictions. Therefore, the matching grant rate from central government to local governments with relatively large agency costs should be relatively high. Although the matching grant rate increases with agency costs even given horizontal fiscal externalities and benefit spillovers among jurisdictions, the horizontal fiscal externalities among jurisdictions decrease the seriousness of the under-provision of public goods caused by agency costs if agency costs in the political agency process are sufficiently large. Accordingly, the matching grant rate from central government to local governments with relatively large agency costs, ceteris paribus, should be appropriately reduced.

\section{Data availability}

We do not analyse or generate any datasets, because our work proceeds within a theoretical and mathematical approach. One can obtain the relevant materials from the references below.

Received: 27 January 2020; Accepted: 16 June 2020;

Published online: 08 July 2020

\section{Notes}

1 Note that agency costs decrease in $V^{\prime} X^{\prime}$ as $V^{\prime} X^{\prime}<0$.

2 See Boadway et al. (1989) and Ogawa (2006).

3 The second-order condition is assumed to be satisfied according to the objective function.

4 Equation (11) can be easily derived by substituting Eq. (10) into Eq. (8)

5 One might argue that an incentive contract using yardstick evaluation may realise the efficient provision of local public goods in full information equilibrium. Furthermore, Nishigaki et al. (2016) also provide a preliminary empirical test that supports these results. However, these cases are explicitly neglected in the analysis.

6 See Zodrow and Mieszkowski (1986), Ogawa (2006), and Kikuchi and Tamai (2019).

7 This is similar to Ogawa (2006). However, agency costs have not been considered in a model of tax competition with benefit spillovers.

8 We assume that the central government's budget constraint must satisfy the hard budget constraint. Thus, the matching grants from central government are only funded by the lump-sum tax.

9 The second-order condition is assumed to be satisfied according to the objective function.

Table 2 Some simulated values for $\beta, n$ and $\frac{v^{\prime} X^{\prime}}{U_{x}}$.

\begin{tabular}{|c|c|c|c|c|}
\hline & $\frac{V^{\prime} X^{\prime}}{U_{x}}=-2$ & $\frac{v^{\prime} X^{\prime}}{U_{x}}=-1$ & $\frac{V^{\prime} X^{\prime}}{U_{x}}=-0.4$ & $\frac{V^{\prime} \boldsymbol{X}^{\prime}}{U_{\mathrm{x}}}=\mathbf{0}$ \\
\hline $\begin{array}{l}\beta=0 \\
n=21\end{array}$ & $\frac{\partial m}{\partial \varepsilon}=-1$ & $\frac{\partial m}{\partial \varepsilon}=0$ & $\frac{\partial m}{\partial \varepsilon}=0.6$ & $\frac{\partial m}{\partial \varepsilon}=1$ \\
\hline $\begin{array}{l}\beta=0.05 \\
n=21\end{array}$ & $\frac{\partial m}{\partial \varepsilon}=-1.525$ & $\frac{\partial m}{\partial \varepsilon}=-0.525$ & $\frac{\partial m}{\partial \varepsilon}=0.075$ & $\frac{\partial m}{\partial \varepsilon}=0.475$ \\
\hline $\begin{array}{l}\beta=\frac{1}{15}(0.067) \\
n=21\end{array}$ & $\frac{\partial m}{\partial \varepsilon}=-1.6$ & $\frac{\partial m}{\partial \varepsilon}=-0.6$ & $\frac{\partial m}{\partial \varepsilon}=0$ & $\frac{\partial m}{\partial \varepsilon}=0.4$ \\
\hline $\begin{array}{l}\beta=0.25 \\
n=21\end{array}$ & $\frac{\partial m}{\partial \varepsilon}=-1.875$ & $\frac{\partial m}{\partial \varepsilon}=-0.875$ & $\frac{\partial m}{\partial \varepsilon}=-0.275$ & $\frac{\partial m}{\partial \varepsilon}=0.125$ \\
\hline $\begin{array}{l}\beta=1 \\
n=21\end{array}$ & $\frac{\partial m}{\partial \varepsilon}=-2$ & $\frac{\partial m}{\partial \varepsilon}=-1$ & $\frac{\partial m}{\partial \varepsilon}=-0.4$ & $\frac{\partial m}{\partial \varepsilon}=0$ \\
\hline
\end{tabular}


10 Under information asymmetry, economic competition among jurisdictional governments also has both positive and negative effects on the underinvestment in jurisdictional infrastructure within a complex decentralised system (see Gorbachuk et al., 2019).

11 Bjorvatn and Schjelderup (2002) shows that there is no incentive for tax competition, if $\beta=1$. In this case, the tax competition distortion is eliminated.

12 Where no agency costs exist in the jurisdictions, the results will be in accordance with the existing literature.

13 See Seabright (1996).

\section{References}

Belleflamme P, Hindriks J (2005) Yardstick competition and political agency problems. Soc Choice Welf 24:155-169

Besley T, Case A (1995) Does electoral accountability affect economic policy choices? Evidence from gubernatorial team limit. Q J Econ 110(3):769-798

Bjorvatn K, Schjelderup G (2002) Tax competition and international public goods. Int Tax Public Financ 9(2):111-120

Boadway R, Pestieau P, Wildasin D (1989) Non-cooperative behavior and efficient provision of public goods. Public Financ/Financ Publiques 44(1):1-7

Brülhart M, Jametti M (2019) Does tax competition tame the Leviathan? J Public Econ 177:1-16

Dahlby B (1996) Fiscal externalities and the design of intergovernmental grants. Int Tax Public Financ 3:397-412

Dahlby B, Wilson LS (2003) Vertical fiscal externalities in a federation. J Public Econ 87:917-930

Gorbachuk V, Dunaievskyi M, Suleimanov S (2019) Modeling of agency problems in complex decentralized systems under information asymmetry. In: 2019 IEEE international conference on Advanced Trends in Information Theory (ATIT), IEEE, Kyiv, Ukraine, pp 449-454. https://doi.org/10.1109/ ATIT49449.2019.9030498

Jensen MC, Meckling WH (1976) Theory of the firm: managerial behavior, agency costs and ownership structure. J Financ Econ 3:305-360

Kawachi K, Ogawa H (2006) Further analysis on public-good provision in a repeated-game setting. FinanzArchiv 62:339-352

Kikuchi Y, Tamai T (2019) Tax competition, unemployment, and intergovernmental transfers. Int Tax Public Financ 26:899-918

Nishigaki Y, Kato H (2016) Yardstick competition and tax competition-intergovernmental relations and efficiency of public goods. In: Proceedings of the 5 th economics and finance conference, International Institute of Social and Economic Sciences, pp 315-331. https://doi.org/10.20472/EFC.2016.005.020

Nishigaki Y, Nishimoto H, Yasugi N, Higashi Y, Wong MS (2016) Yardstick competition, performance evaluation, and the efficient provision of local public goods. J Adv Manag Sci 4(2):141-145
Ogawa H (2006) Tax competition, spillovers, and subsidies. Ann Reg Sci 40:849-858

Seabright P (1996) Accountability and decentralization in government: an incomplete contracts model. Eur Econ Rev 40:61-89

Wrede M (2001) Yardstick competition to tame the Leviathan. Eur J Political Econ 17:705-721

Zodrow GR, Mieszkowski P (1986) Pigou, Tiebout, property taxation, and the underprovision of local public goods. J Urban Econ 19:356-370

\section{Acknowledgements}

We thank Seamus Harris, M.A., from Liwen Bianji, Edanz Editing China for editing the English text of a draft of this manuscript.

\section{Competing interests}

The author declares no competing interests.

\section{Additional information}

Correspondence and requests for materials should be addressed to T.Y.

Reprints and permission information is available at http://www.nature.com/reprints

Publisher's note Springer Nature remains neutral with regard to jurisdictional claims in published maps and institutional affiliations.

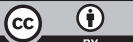

Open Access This article is licensed under a Creative Commons Attribution 4.0 International License, which permits use, sharing, adaptation, distribution and reproduction in any medium or format, as long as you give appropriate credit to the original author(s) and the source, provide a link to the Creative Commons license, and indicate if changes were made. The images or other third party material in this article are included in the article's Creative Commons license, unless indicated otherwise in a credit line to the material. If material is not included in the article's Creative Commons license and your intended use is not permitted by statutory regulation or exceeds the permitted use, you will need to obtain permission directly from the copyright holder. To view a copy of this license, visit http://creativecommons.org/ licenses/by/4.0/

(C) The Author(s) 2020 